\title{
Impact of Weight Management Programme on Anthropometric and Biochemical Parameters of Overweight/ Obese Adults
}

\author{
Shweta Sharma ${ }^{1}$ and Meenu Aggarwal ${ }^{2}$ \\ ${ }^{1}$ Indira Gandhi National Open University, Shyama Prasad Mukherji College, University of Delhi, India \\ ${ }^{2}$ Associate Professor, Shyama Prasad Mukherji College, University of Delhi, India \\ *Corresponding author: meenuag63@gmail.com
}

Received: $17-03-2018$

Revised: $18-04-2018$

Accepted: 27-05-2018

\begin{abstract}
This study was conducted to find efficacy of weight management programme on forty one adults attending weight loss clinic in Gurgaon. At baseline eighteen (44\%) were overweight and remaining 56\% were in different stages of obesity. Their weight, height, waist circumference, hip circumference and different biochemical parameters were taken at base line. They all underwent the weight management programme of three months involving- Dietary modification ( high fiber diet providing 1200-1500 Kcal, 50-60 g protein and $20 \mathrm{~g}$ of fat per day), physical activity for 30-45 minutes, counseling sessions two to three times a week. After three months there was significant reduction in mean weight, mean height, mean waist and mean hip circumference. Though changes in BMI Index and waist hip ratio were non-significant. Significant reduction in fasting blood sugar and triglyceride level was observed. Other biochemical parameters showed nonsignificant changes. Thus weight management programme was found to be effective in improving anthropometric and biochemical parameters even in short duration of six months.
\end{abstract}

Keywords: BMI, Dietary, weight management programme, biochemical parameters, Obesity and overweight

Obesity and overweight represent a rapidly growing threat to the health of population in an increasing number of countries. Globally, in 2005, approximately 1.6 billion adults were overweight and at-least 400 million adults were obese. Once considered a problem of high income countries, overweight and obesity are now on rise in low and middle income countries, as well, particularly in urban settings (WHO, 2006).

Obesity is basically due to positive energy balance of the body resulting from excessive energy intake and low activity level, or it could be due to genetic factors, emotional eating out, sedentary life style and high fat, energy dense diet (Gill et al. 2005).

Obesity is a major risk factor for high morbidity and mortality. Its association with hyperlipidemia, hyperglycemia and insulin resistance is well established. Diseases such as coronary heart diseases, hypertension, diabetes, certain cancers, some reproductive problems are also associated with obesity (Deurenberg et al. 2001).

Obesity interventions which have proven to be effective include long term behaviour modifications, decreased sedentary life style, dietary modifications and family support for emotional and motivational reasons (Batch and Baur 2005; Cretikos et al. 2008).

\section{METHODOLOGY}

The research was designed to study the effectiveness 
of weight management programme on overweight/ obese adults in terms of anthropometric and biochemical parameters.

The study was carried out in a weight management clinic in Gurgaon, Haryana.

The study unit was an overweight/obese adult of either gender. BMI above 25 was used to define overweight and above 30 to define obese condition.

A total of fifty subjects were enrolled for weight management programme. Their anthropometric measurements and biochemical estimations were done at time of enrolment. With help of an interview schedule their general profile, physical activity level, dietary habits were assessed. They were given a special diet, diet counseling and physical exercise regime. They were monitored for a period of three months. At the end of three months, 41 subjects had been able to follow the weight management programme. Data of these 41 subjects was used for analysis.

\section{RESULTS AND DISCUSSION}

The study was undertaken to find effectiveness of weight management programme on overweight/ obese adults in terms of anthropometric and biochemical parameters. Study was conducted in a weight management clinic for a period of three months. Data of 41 subjects who had completed the study was used for analysis. Out of these $14(34 \%)$ were men and $27(66 \%)$ were women. Their age was in range of $20-69$ years.

The three stages of study were:

1. Baseline Data Collection

2. Intervention Programme of three months

3. Follow up data collection during and after three months

\section{Baseline Data Collection}

At baseline i.e. before commencement of intervention programme, data was collected about their general profile, dietary habits, anthropometric and biochemical parameters.
They belonged to middle or upper middle income group. They were leading a sedentary life style. The main leisure time activities of subjects were watching television $(70 \%)$ or time with computer games $(30 \%)$. Similar results have been reported in a study on Irish overweight and obese individuals who had low physical activity level and T.V. viewing occupied most of their time (McCarthy et al. 2002). Association of Television viewing time with obesity was also reported in a study in South India (Kuriyan et al. 2007)

In terms of dietary habits $18(44 \%)$ were vegetarians and remaining 23 (56\%) were non vegetarians. Fried snacks like samosa, Pakora and chips were favorites of twelve (29\%) subjects. Sweet tooth (special fondness for sweets/chocolates/ice creams) was reported by seventeen $(41 \%)$ subjects. Consumption of sweetened fruit juice/aerated drinks on daily basis was reported by five $(12 \%)$ subjects. Fried snacks, chocolates, biscuits and bhujia were the most common items consumed in between the meals. Similar findings have been reported in a study conducted in Ludhiana, Punjab (Amandeep et al. 2007).

Nibbling in between meals, eating at night due to insomnia and consumption of refined, starchy and fatty food contributed to a high energy intake. It was seen that most of the subjects were consuming excess fat in their diet. It was also seen that most of them were also in habit of eating out at least once a week. In general most of them had unhealthy eating habits which could be the main reason for them being overweight or obese.

At base line their weight, height, waist and hip circumference was taken. From these values their BMI (Body mass index), WHR (waist hip ratio) was also calculated. Biochemical parameters recorded at base line were blood sugar, lipid profile, liver, kidney and thyroid functioning tests as well as blood pressure.

\section{Intervention Programme}

Theintervention was three pronged involving- dietary modification, physical activity and counseling. 
Dietary modification: The dietary modification serves as guide for overweight/obese individuals to make healthy food choices. During three months intervention programme, subjects were given diets which provided $1200-1500 \mathrm{Kcal}, 50-60 \mathrm{~g}$ of protein and 20 grams of fat per day. All 41 subjects adhered to these diets as was revealed from their 24 hours dietary recall taken two to three times per week during entire period of intervention. A high fibre diet was used in the intervention programme as there is epidemiological support that high dietary fibre intake reduces obesity. Many mechanisms have been suggested for how dietary fibre aids in weight management, including promoting satiation, decreasing absorption of macronutrients and altering secretion of gut hormones (Slavin, 2005).

Physical Activity: Exercise plays an important role in initiating and sustaining weight loss along with dietary and lifestyle modifications. It helps in increasing the lean body mass in proportion to fat. Exercise burns glycogen stores paving the way for fat to be used as fuel (Weltman, 2001). In this study during intervention phase subjects adopted an exercise programme of 30-45 minutes per day (Table 1)

Table 1: Physical Exercise adopted during intervention programme

\begin{tabular}{llll}
\hline $\begin{array}{l}\text { Physical } \\
\text { Exercise }\end{array}$ & $\begin{array}{l}\text { Men (N=14) } \\
\mathbf{n}(\mathbf{\%})\end{array}$ & $\begin{array}{l}\text { Women } \\
\mathbf{( N = 2 7 )} \\
\mathbf{n}(\%)\end{array}$ & $\begin{array}{l}\text { Total } \\
\mathbf{n}(\mathbf{\%})\end{array}$ \\
\hline Walking & $4(28.5 \%)$ & $17(62.9 \%)$ & $21(51.2 \%)$ \\
Yoga & 0 & $5(18.5 \%)$ & $5(12.1 \%)$ \\
Gym & $5(35.7 \%)$ & $5(18.5 \%)$ & $10(24.3 \%)$ \\
Jogging & $3(21.4 \%)$ & 0 & $3(7.3 \%)$ \\
Tennis & $2(14.2 \%)$ & 0 & $2(4.9 \%)$ \\
\hline
\end{tabular}

The results indicated that the most common physical exercise was walking $(51.2 \%)$, followed by going to gym $(24.3 \%)$. Yoga was practiced only by women while jogging and playing tennis was adopted as physical exercise by men only. During moderate exercise there is a shift to greater use of fat as fuel. Physical activity becomes an important component of effective intervention to enhance weight loss. Participation in at least 30 minutes of daily physical exercise that is at least moderate in intensity has been recommended in many studies so as to facilitate long term weight control (Jackicic and Otto, 2006).

Counseling: Counseling is required for motivation and psychological support. In this study, subjects were given 2-3 counseling sessions two to three times a week during entire intervention period of three months. They were motivated to lose weight and were given clarifications about diet plan and physical activity regime. They were advised to improve their physical activity level throughout the day if possible.

Counselling was especially given in terms of portion size, selection of food, cooking with minimal amount of fat and suggestions about different low fat recipes. Importance of clear soups, fruits and salads were reinforced in each counseling session.

Symptomatic problems like constipation, water retention and abdominal discomfort were reported by few subjects during intervention programme. This could be due to change in their diet pattern especially due to high fibre diet during intervention programme. In mild cases of constipation, fruit intake of ripe papaya, guava, apple etc. was increased. Subjects were also asked to increase their water intake. Salt reduction was suggested in cases of water retention. Diet plan was changed from time to time according to their likes and dislikes and success in weight loss. Special cravings for food/sugar were also taken into consideration and suitable options were given to subjects.

\section{Follow up data}

After three months of intervention, their anthropometric measurements (weight, waist and hip circumference) were measured every month, however values obtained after a period of three months were used for data analysis. Biochemical parameters were also repeated after three months.

Impact on obesity in terms of anthropometric measurements: It was measured in terms of weight loss, reduction in waist and hip circumference, BMI and Waist Hip Ratio. 
Weight Loss: The analysis of follow up data revealed that all subjects had lost weight. The mean weight of subjects at baseline was $86.4 \mathrm{Kg}$ and after three months of intervention it was $78.9 \mathrm{Kg}$. Thus, a loss of $7.5 \mathrm{Kg}$ occurred due to intervention programme of three months. This difference was found to be significant as tested by $t$ test $(\mathrm{p}<0.05)$.

Impact on Body Mass Index (BMI): At baseline and after three months of intervention weight and height of subjects were taken. From this their BMI \{weight $(\mathrm{Kg}) /$ height $^{2}$ (meters) $\}$ was calculated. BMI eliminates dependence on frame size and thus proves to be an important tool to measure obesity. On the basis of these values they were classified in grades of obesity or overweight (Table 2).

Table 2: Change in BMI Index of subjects due to Intervention programme

\begin{tabular}{|c|c|c|c|}
\hline $\begin{array}{l}\text { Weight } \\
\text { Status }\end{array}$ & BMI Range & $\begin{array}{l}\text { Baseline } \\
\text { Values }(\mathrm{N}=41) \text {, } \\
\text { n }(\%)\end{array}$ & $\begin{array}{l}\text { Follow up } \\
\text { Values } \\
\mathrm{N}=41, \mathrm{n}(\%)\end{array}$ \\
\hline Normal & $18.5-24.9$ & Nil & $5(12.1 \%)$ \\
\hline Overweight & $25-29.9$ & $18(44 \%)$ & 17 (41.4\%) \\
\hline $\begin{array}{l}\text { Obesity } \\
\text { (Grade I) }\end{array}$ & $30-34.9$ & $11(27 \%)$ & $9(21.9 \%)$ \\
\hline $\begin{array}{l}\text { Obesity } \\
\text { (Grade II) }\end{array}$ & $35-39.9$ & $9(22 \%)$ & $8(19.5 \%)$ \\
\hline $\begin{array}{l}\text { Obesity (grade } \\
\text { III) }\end{array}$ & 40 and above & $3(7 \%)$ & $2(4.9 \%)$ \\
\hline
\end{tabular}

\section{Chi square test-non significant}

Analysis of BMI values revealed that twelve subjects moved to a lower grade of obesity. One subject moved from grade III of obesity to grade II, two subjects moved from grade II to grade I of obesity, four subjects from grade I of obesity to overweight while five subjects from overweight to normal weight range.

Thus a clear trend of improvement in terms of BMI grades could be seen, however, these results were not significant as tested by chi square.

Impact on Waist and Hip Circumference: At baseline, mean waist circumference of subjects was $97.6 \mathrm{~cm}$. which reduced to $90.8 \mathrm{~cm}$.after intervention. Thus a mean reduction of $6.8 \mathrm{~cm}$. was found and it was significant as tested by $t$ test. Mean hip circumference at baseline was $113.7 \mathrm{~cm}$. Which reduced to $105.8 \mathrm{~cm}$. After intervention. Thus a mean reduction of $7.9 \mathrm{~cm}$. was found and it was significant as tested by $t$ test. $(\mathrm{p}<0.5)$.

Impact on Waist Hip Ratio: Waist and hip circumference of subjects was used to calculate their Waist Hip ratio (WHR). Two individuals who have the same BMI and the same total body fat may have different abdominal fat. Accumulation of abdominal fat increases the risk of number of chronic degenerative diseases (Ghosh, 2006). Men who had WHR more than 1 were considered to have abdominal obesity while women with WHR of more than 0.85 were considered to have abdominal obesity.

At base line 25 (61\%) subjects had normal WHR while $16(39 \%)$ had abdominal obesity. Out of these 5 were men and 11 were women. After intervention, five subjects- two men and three women could reduce their Waist/Hip ratio to less than 1 and 0.85 respectively (Table 3 ).

Table 3: Changes in Waist Hip Ratio of subjects due to Intervention Programme

\begin{tabular}{lll}
\hline $\begin{array}{l}\text { Waist Hip Ratio } \\
\text { (Abnormal) }\end{array}$ & Baseline & $\begin{array}{l}\text { Follow up } \\
\text { (After three } \\
\text { months) }\end{array}$ \\
\hline Men, $>1(\mathrm{n}=14)$ & $5(36 \%)$ & $3(21 \%)$ \\
Women, $>0.85(\mathrm{n}=27)$ & $11(41 \%)$ & $8(30 \%)$ \\
Total with abnormal WHR & $16(39 \%)$ & $11(27 \%)$ \\
Total with normal WHR & $25(61 \%)$ & $30(67 \%)$ \\
\hline
\end{tabular}

At baseline 39\% subjects had abnormal WHR which reduced to $27 \%$ after intervention. However, these differences in WHR were not found to be significant as tested by chi square.

\section{Impact on Biochemical Parameters}

At baseline various biochemical parameters were checked and these were again checked after intervention programme of three months to see if there were any changes. 
Blood Sugar (Fasting): Insulin resistance has been proposed as a link between obesity, glucose intolerance, hypertension and cardio vascular problems. At base line $12(29.2 \%)$ subjects had abnormal (>100mg/dl.) fasting blood sugar levels. Nine $(21.9 \%)$ showed improvement, that is their fasting blood sugar level came below $100 \mathrm{mg} / \mathrm{dl}$. All these nine subjects had only marginally high levels in the beginning. Diet restriction, increased physical activity and modified diet could bring this improvement in short duration of three months. Differences in mean values of fasting blood sugar level at base line and follow up were found to be significant as tested by $\mathrm{t}$ test.

Lipid Profile: The purpose of blood lipid testing is to determine whether abnormally high or low concentrations of a specific lipid are present. Cholesterol is a primary component of the plaques that form in atherosclerosis and is therefore the major risk factor for the rapid progression of coronary artery disease (CAD). Diet influences the serum lipid as well as serum total cholesterol, low density lipoprotein (LDL)-cholesterol and HDL cholesterol and thus influence the risk of atherosclerosis and CHD (Misra et al. 2003; Khanna et al. 1997).

Table 4: Changes in Lipid Profile due to Intervention Programme

\begin{tabular}{lll}
\hline $\begin{array}{l}\text { Lipid Profile } \\
\text { (abnormal) }\end{array}$ & $\begin{array}{l}\text { Base line Data } \\
\text { N=41, n (\%) }\end{array}$ & $\begin{array}{l}\text { Follow up data } \\
\text { (After three } \\
\text { months), N=41, n } \\
(\%)\end{array}$ \\
\hline $\begin{array}{l}\text { Total Cholesterol } \\
(>200 \mathrm{mg} / \mathrm{dl})^{\mathrm{ns}}\end{array}$ & $11(26.8 \%)$ & $6(14.6 \%)$ \\
LDL $(>100 \mathrm{mg} / \mathrm{dl})^{\mathrm{ns}}$ & $25(60 \%)$ & $14(34.1 \%)$ \\
VLDL $(>30 \mathrm{mg} / \mathrm{dl})^{\mathrm{ns}}$ & $14(34.1 \%)$ & $7(17 \%)$ \\
$\begin{array}{l}\text { Triglyceride* } \\
(>150 \mathrm{mg} / \mathrm{dl})\end{array}$ & $9(21.9 \%)$ & $3(7.3 \%)$ \\
\hline
\end{tabular}

ns=non-significant, * significant as tested by $t$ test.

Improvement in lipid profile was observed as total cholesterol level remained higher only in six subjects out of eleven subjects at baseline, LDL level higher in only fourteen subjects out of twenty five subjects as base line. Similarly seven (17\%) subjects showed improvement in the VLDL level from a baseline of fourteen $(34.1 \%)$ subjects. However comparison of mean values at baseline and after intervention for these parameters were not found to be significant as tested by t test.

Triglycerides are produced after digestion of fats. Although they are not a component of the plaque associated with atherosclerosis, they increase the viscosity of blood and promote obesity, which can contribute to coronary disease. In this study, nine $(21.9 \%)$ subjects had high triglyceride levels as baseline but at follow up stage only three (7.3\%) had high levels. The mean values of triglyceride at baseline and after intervention were significantly different as tested by $t$ test $(p=0.03)$. This proves that dietary intervention programme was effective in improving lipid profile of subjects.

Liver Functioning Test: Obesity is associated with liver abnormalities known as nonalcoholic fatty liver disease. Obesity can damage liver cells which leads to increase in liver enzymes in serum. Weight loss and exercise can prevent complications of fatty liver. In this study functioning of liver of subjects was checked with the help of following liver enzymes testsSGOT (Serum glutamic oxalo acetic transaminase), SGPT (Serum Glutamic Pyruvic Transaminase) and Alkaline Phosphatase (Table 5).

Table 5: Liver Functioning Tests

\begin{tabular}{lll}
\hline $\begin{array}{l}\text { Liver Functioning } \\
\text { Tests (Abnormal) }\end{array}$ & $\begin{array}{l}\text { Baseline Data } \\
(\mathbf{N = 4 1 )} \mathbf{n}(\mathbf{\%})\end{array}$ & $\begin{array}{l}\text { Follow up Data } \\
\mathbf{( N = 4 1 )} \mathbf{n}(\mathbf{\%})\end{array}$ \\
\hline SGOT $(>37 \mathrm{U} / \mathrm{L})$ & $4(9.7 \%)$ & $4(9.7 \%)$ \\
SGOT $(>37 \mathrm{U} / \mathrm{L})$ & $7(17 \%)$ & $7(17 \%)$ \\
SGOT $(>37 \mathrm{U} / \mathrm{L})$ & $3(7.3 \%)$ & $3(7.3 \%)$ \\
\hline
\end{tabular}

At baseline four, seven and three subjects had abnormally high values of SGOT, SGPT and alkaline phosphatase respectively. These values did not reveal any change after intervention. This indicates that intervention programme of three months was not sufficient to bring improvement in liver functioning. 
Thyroid Functioning Test: Thyroid produces hormone Thyroxine (T4), some of it gets converted to T3 (Triiodothronine). Their secretion is controlled by another hormone called TSH (Thyroid stimulating hormone). T3 value of less than $60 \mathrm{ng} / \mathrm{di}$, T4 value of less than $4.5 \mathrm{cg} / \mathrm{dl}$ and TSH value of more than 5.5 $\mathrm{mlU} / \mathrm{l}$ indicates hypothyroidism. Hypothyroidism leads to lower metabolic rate and hence can lead to overweight and obesity. Studies have reported improvement in T3, T4 and reduction in TSH on account of weight loss and physical exercise. In this study thyroid functioning tests were done at baseline and at follow up stage.

Table 6: Thyroid Functioning Tests

\begin{tabular}{lll}
\hline $\begin{array}{l}\text { Thyroid } \\
\text { Functioning Tests } \\
\text { (Abnormal) }\end{array}$ & $\begin{array}{l}\text { Baseline Data } \\
(\mathbf{N}=41)\end{array}$ & $\begin{array}{l}\text { Follow up Data } \\
\mathbf{( N = 4 1 )}\end{array}$ \\
\hline $\mathrm{TSH}(>5.5 \mu \mathrm{lU} / \mathrm{ml})$ & $11(26.8 \%)$ & $5(12.1 \%)$ \\
$\mathrm{T} 3(>181 \mathrm{ng} / \mathrm{dl})$ & $4(9.7 \%)$ & $4(9.7 \%)$ \\
$\mathrm{T} 4(>12.6 \mu \mathrm{g} / \mathrm{dl})$ & $1(2.4 \%)$ & $1(2.4 \%)$ \\
\hline
\end{tabular}

At baseline eleven (26.8\%) subjects had abnormal TSH, while after intervention only five (12.1\%) subjects had abnormal TSH. However, $\mathrm{t}$ test conducted on mean values of TSH before and after intervention did not reveal any significant result. The number of subjects with low T3 and low T4 showed no change at follow up stage.

Hypertension: Hypertension and obesity are often co related. It was seen that at baseline out of forty one subjects, ten $(24.3 \%)$ were suffering from high blood pressure. Seven subjects out of these ten subjects had abnormal WHR, indicating coexistence of abdominal obesity and hypertension.

After intervention programme, the number of subjects with normal blood pressure increased from baseline number of $31(75.6 \%)$ to $36(87.8 \%)$. However five $(12.2 \%)$ subjects had high blood pressure even after intervention programme. The results were not significant as tested by chi square.

\section{CONCLUSION}

It was clear from the study that main cause of obesity/ overweight appeared to be faulty eating habits and sedentary life style. Overweight /Obese subjects had associated problems like hypertension/ high fasting blood sugar levels/ hypothyroidism/dyslipidemia / abnormal liver functioning.

A weight management programme involving calorie reduction, diet modification combined with exercise regime and counseling could bring out significant reduction in mean weight, mean waist and mean hip circumference of subjects even during a short span of three months. However results were not significant in terms of improvement to lower grades of BMI or to normal WHR.

The intervention programme could bring reduction in problems of hypertension/high fasting blood sugar levels/hypothyroidism and dyslipidemia among subjects. However, the results were significant in terms of reduction of triglycerides and fasting blood sugar levels only.

It can thus be concluded that weight management programme involving calorie reduction, dietary modification, exercise regime and regular counseling can be very effective in solving the problem of obesity and associated complications in long run. Adoption of the intervention programme for a longer duration is likely to bring about more significant results in terms of anthropometric and biochemical parameters.

\section{REFERENCES}

Amandeep, K.P., Jasvinder, S. and Navjot, K. 2007. Dietary intake pattern of overweight children. Journal of Indian Dietetic Association, 32(2): 1-7.

Batch, J.A. and Baur, L.A. 2005. Management and prevention of obesity and its complications in children and adolescents. Med. J. Aust., 182(3): 130-5.

Cretikos, M.A. and Valenti, L. 2008. General practice management of overweight and obesity in children and adolescents in Australia. Med. Care, 46(11): 1163-69.

Deurenberg, Y.M., Chew, S.K. and Lin, V.F. 2001. Relationships between indices of obesity and its co-morbidities in multi -ethnic Singapore. Int. J. Obes. Relat. Metab. Disord., 25(10): 1554-62. 
Gill, T., King, L. and Caterson, I. 2005. Obesity prevention: necessary and possible- a structured approach for effective planning. Proc. Nutr. Soc., 64(20): 255-61.

Jakicic, J.M. and Otto, A.D. 2006. Treatment and prevention of obesity: what is the role of exercise? Nutr Rev., 64(2 Part 2): S57-61.

Khanna, K., Gupta, S., Seth, R., Passi, S.J., Puri, S. and Mahana, R. 2001. Textbook of Nutrition and Dietetics, Phonenix Publication, pp. 187-208.

Kuriyan, R., Bhat, S. and Thomas, T. 2007. Television viewing and sleep are associated with overweight among urban and semi urban South Indian children. Nutri. J., 6: 25.

McCarthy, S.N., Gibney, M.J. and Flynn, A. 2002. Overweight, obesity and physical activity levels in Irish adults: evidence from the North/ South Ireland food consumption survey. Proc. Nutr. Soc., 61(1): 3-7.
Misra, A., Pandey, R.M. and Sinha, S. 2003. Receiver operating characteristics curve analysis of body fat and body mass index in dyslipidaemic Asian Indians. Indian J. Med. Res., 117: 170-9.

Slavin, J.L. 2005. Dietary fibre and body weight. Nutrition, 21(3): 411-18.

Weltman, A., Weltman, J.Y., Veldhuis, J.D. and Hartman, M.L. 2001. Body composition, physical exercise, growth hormone and obesity. International J. of Eating and Weight Disorders, 6(3 supply): 28-37.

WHO. 2006. http://www.who.int/mediacentre/factsheets/ fs311/en/index.html. 